\title{
Structural plasticity of staphylococcal nuclease probed by perturbation with pressure and pH
}

\author{
Ryo Kitahara, ${ }^{1}$ Kazumi Hata, ${ }^{2}$ Akihiro Maeno, ${ }^{2}$ Kazuyuki Akasaka, ${ }^{2}$ Michael S. Chimenti, ${ }^{3, \dagger}$ \\ Bertrand Garcia-Moreno E., ${ }^{3}$ Martin A. Schroer, ${ }^{4}$ Christoph Jeworrek, ${ }^{5}$ Metin Tolan, ${ }^{4}$ \\ Roland Winter, ${ }^{5}$ Julien Roche, ${ }^{6}$ Christian Roumestand, ${ }^{6}$ Karine Montet de Guillen, ${ }^{6}$ \\ and Catherine A. Royer ${ }^{6 *}$ \\ ${ }^{1}$ College of Pharmaceutical Sciences, Ritsumeikan University, Shiga, Japan \\ ${ }^{2}$ High Pressure Research Center, Kinki University, Wakayama, Japan \\ ${ }^{3}$ Department of Biophysics, The Johns Hopkins University, Baltimore, MD \\ ${ }^{4}$ Fakultät Physik/DELTA, Technical University of Dortmund, Germany \\ ${ }^{5}$ Department of Chemistry, Technical University of Dortmund, Germany \\ ${ }^{6}$ Centre de Biochimie Structurale, INSERM U554, CNRS UMR 5048, Université de Montpellier, France
}

\section{ABSTRACT}

The ionization of internal groups in proteins can trigger conformational change. Despite this being the structural basis of most biological energy transduction, these processes are poorly understood. Small angle X-ray scattering (SAXS) and nuclear magnetic resonance (NMR) spectroscopy experiments at ambient and high hydrostatic pressure were used to examine how the presence and ionization of Lys-66, buried in the hydrophobic core of a stabilized variant of staphylococcal nuclease, affect conformation and dynamics. NMR spectroscopy at atmospheric pressure showed previously that the neutral Lys-66 affects slow conformational fluctuations globally, whereas the effects of the charged form are localized to the region immediately surrounding position 66 . Ab initio models from SAXS data suggest that when Lys-66 is charged the protein expands, which is consistent with results from NMR spectroscopy. The application of moderate pressure $(<2 \mathrm{kbar})$ at $\mathrm{pH}$ values where Lys-66 is normally neutral at ambient pressure left most of the structure unperturbed but produced significant nonlinear changes in chemical shifts in the helix where Lys-66 is located. Above 2 kbar pressure at these $\mathrm{pH}$ values the protein with Lys-66 unfolded cooperatively adopting a relatively compact, albeit random structure according to Kratky analysis of the SAXS data. In contrast, at low $\mathrm{pH}$ and high pressure the unfolded state of the variant with Lys-66 is more expanded than that of the reference protein. The combined global and local view of the structural reorganization triggered by ionization of the internal Lys- 66 reveals more detectable changes than were previously suggested by NMR spectroscopy at ambient pressure.

Proteins 2011; 79:1293-1305.

(C) 2010 Wiley-Liss, Inc.
Key words: protein electrostatics; conformational dynamics; pressure; NMR; SAXS.

Despite significant progress in our understanding of protein folding and stability, important questions concerning the structural basis of folding cooperativity and the structural, thermodynamic, and dynamic origins of barriers between conformational states remain unanswered. This has hindered our understanding of the structural basis of important biochemical processes such as catalysis and energy transduction, which are governed partly by the response of proteins to changes in the charged state of $\mathrm{H}^{+}$or $\mathrm{e}^{-}$binding centers. To examine this problem in detail, we applied NMR spectroscopy and SAXS at ambient and high-hydrostatic pressure to monitor the consequences of the ionization of Lys-66 in the V66K variant of staphylococcal nuclease (SNase).

Additional Supporting Information may be found in the online version of this article. Grant sponsor: CAR et CR INSERM, the CNRS, and the ANR PiriBio; Grant number: 09-455024; Grant sponsor: B.G-M.E., NIH; Grant number: NIH grant GM061597 and NSF grant MCB-0743422; Grant sponsor: RW Deutsche Forschungsgemeinschaft (DFG); Grant sponsor: KA Academic Frontier Program of the Ministry of Education, Culture, Sports, Science and Technology of Japan (MEXT); Grant sponsor RK: 1) Grant-in-Aid for JSPS Fellows and Grant-in-Aid for Scientific Research on Innovative Area of MEXT MAS would like to acknowledge the Deutsche Forschungsgemeinschaft (DFG TO169/14-1) for financial support. The BL9 and BW4 beamline crews and the machine groups of DELTA and HASYLAB are kindly acknowledged. For their excellent help during the SAXS beamtimes we thank M. Paulus, C. Sternemann, D.C.F. Wieland, Ch.J. Sahle, A. Steffen and S. Tiemeyer.

${ }^{\dagger}$ Present address: Department of Pharmaceutical Chemistry, University of California San Francisco.

${ }^{\star}$ Correspondence to: Catherine A. Royer, Centre de Biochimie Structurale, INSERM U554, CNRS UMR 5048 Université de Montpellier, France. E-mail: royer@cbs.cnrs.fr. Received 24 August 2010; Revised 1 November 2010; Accepted 29 November 2010 Published online 13 December 2010 in Wiley Online Library (wileyonlinelibrary. com). DOI: $10.1002 /$ prot. 22966 
SNase is a rich model system for detailed examination of structural plasticity and structure-energy correlations. The thermodynamic stability of SNase can be modulated with mutagenesis and increased from $5.4 \mathrm{kcal} \mathrm{mol}^{-1}$ for the wild-type protein ${ }^{1}$ to nearly $12 \mathrm{kcal} \mathrm{mol}^{-1}$ for two highly stable variants known as NVIAGA ${ }^{2}$ and $\Delta+\mathrm{PHS}^{3}$. The $\Delta+$ PHS protein, engineered by a deletion (44 to 49 ) and five substitutions (P117G, H124L and S128A, G50F and $\mathrm{V} 15 \mathrm{~N}$ ), is of special interest because it has been shown to tolerate the presence and ionization of groups buried in its hydrophobic core. ${ }^{3-10}$ The majority of variants of $\Delta+$ PHS with internal ionizable groups retain a folded structure and cooperative unfolding profiles, 4,8 even when the internal groups are charged. The present study is focused on the V66K variant of $\Delta+$ PHS. Lys-66 titrates with a $\mathrm{p} K_{\mathrm{a}}$ of 5.7 , which is highly depressed relative to the normal $\mathrm{p} K_{\mathrm{a}}$ of 10.4 for Lys in water. ${ }^{3,6}$ This depressed $\mathrm{p} K_{\mathrm{a}}$ suggests that the interior of SNase is not as good a solvent as water; hence, the charged form of the amino group is destabilized relative to its neutral form. 6

Besides destabilizing the native state of a protein, the presence and ionization of a group buried in the hydrophobic core can trigger changes in conformation and dynamics, and could stabilize partially unfolded excited states in which the internal charge group can interact with water. This is precisely why internal ionizable groups can be useful for mapping the folding free energy landscape of proteins. ${ }^{5,11}$ The crystal structures of V66K variants of SNase are not particularly informative; they are indistinguishable from those of the reference $\Delta+$ PHS protein. $1,3,9$ In the structures obtained under conditions of $\mathrm{pH}$ where Lys-66 is neutral, the side chain of Lys-66 is buried deeply in the hydrophobic core of the protein, nearly $12 \AA$ from the protein-water interface. In the structure obtained under conditions of $\mathrm{pH}$ where Lys-66 is charged, the backbone of the protein is unaffected but the side chain is disordered. ${ }^{9}$ Structure-based $\mathrm{p} K_{\mathrm{a}}$ calculations with a variety of electrostatics models show that the behavior of Lys-66 is consistent with high-apparent polarizability in the hydrophobic interior of the protein; ${ }^{6}$ however, the crystal structures provide no clues into the origins of this high-apparent polarizability. Experiments and calculations suggest that it is related to conformational changes coupled to the ionization of the internal Lys-66.5,8,9 These are precisely the type of relaxation processes we wish to understand.

Because the $\mathrm{p} K_{\mathrm{a}}$ of Lys-66 is very depressed, it is possible to use $\mathrm{pH}$ perturbation to exert electrostatic and conformational stress on the V66K protein. NMR spectroscopy at atmospheric pressure was used previously to show that at $\mathrm{pH} 7$, where Lys-66 is buried and neutral, ${ }^{5}$ the V66K substitution affects the hydrogen exchange behavior throughout the protein, probably because the global thermodynamic stability of the protein is greatly diminished even when the internal Lys-66 is neutral. When Lys-66 is charged only the region immediately adjacent to the ionizable side chain is affected. ${ }^{5}$ Specifically, in ${ }^{15} \mathrm{~N}-{ }^{1} \mathrm{H}$ HSQC spectra, the resonances of backbone amides of residues 62-70 are broadened when these internal ionizable groups are charged; the rest of the protein appears to remain unaffected. This is consistent with an increase in local fluctuations concomitant with the ionization of Lys-66, but the exact nature of the fluctuations remains to be established. It is interesting that although burial and ionization of Lys66 diminishes the thermodynamic stability of the protein significantly, the structural and dynamic consequences appear to be relatively minor. 8,10

In an attempt to improve our understanding of the effects of the ionization of Lys-66 on structure and dynamics over a wide range of timescales, we have monitored the effects of changes in $\mathrm{pH}$ concomitantly with nuclear magnetic resonance spectroscopy (NMR) and small angle X-ray scattering (SAXS). Because the $\mathrm{pH}$ sensitivity of this protein originates primarily from differences in hydration of the Lys residue when it is in water and when it is buried in a hydrophobic pocket, highhydrostatic pressure was also used in attempts to perturb the native and unfolded state manifolds. Our interest in using high-hydrostatic pressure to examine the effects of internal polar and ionizable groups on conformational stability and dynamics stems from the promise of pressure as a useful tool for studying equilibrium processes governed by changes in water-inaccessible volume. ${ }^{12,13}$ The utility of pressure as a useful thermodynamic variable to examine processes affected by electrostatic hydration was already revealed by pressure-jump relaxation studies with variants of SNase with internal ionizable groups. ${ }^{14,15}$ Those studies showed that the hydration of the transition state ensemble can be affected dramatically by substitution with ionizable groups at positions that are normally part of the main hydrophobic core in the transition state ensemble of the wild-type protein. Although the effects of substitutions of hydrophobic positions with ionizable groups are subtle, the effects on the free-energy landscape can be very significant. 14,15

Application of hydrostatic pressure constitutes a unique and gentle thermodynamic perturbation to proteins. High-pressure selectively stabilizes conformations with smaller specific volumes. The working hypothesis, 16 based on earlier studies on SNase ${ }^{14-19}$ and the c-Myb R2 domain $^{20}$ is that the differences in volume between the various conformational states of proteins arise primarily from differences in their solvent excluded void volumes. Indeed, although the interior of proteins is generally quite well packed, packing is not perfect; hence there is unoccupied space inside proteins, some of which can be filled by water in locally unfolded states or on complete unfolding. ${ }^{12,13}$ The molar volume decreases as cavities become hydrated; therefore, the application of pressure is expected to stabilize progressively the lower volume conformers with higher degree of hydration in cavities. In principle, subtle conformational fluctuations that are unnoticed at ambient pressure can be enhanced with high pressure to levels 

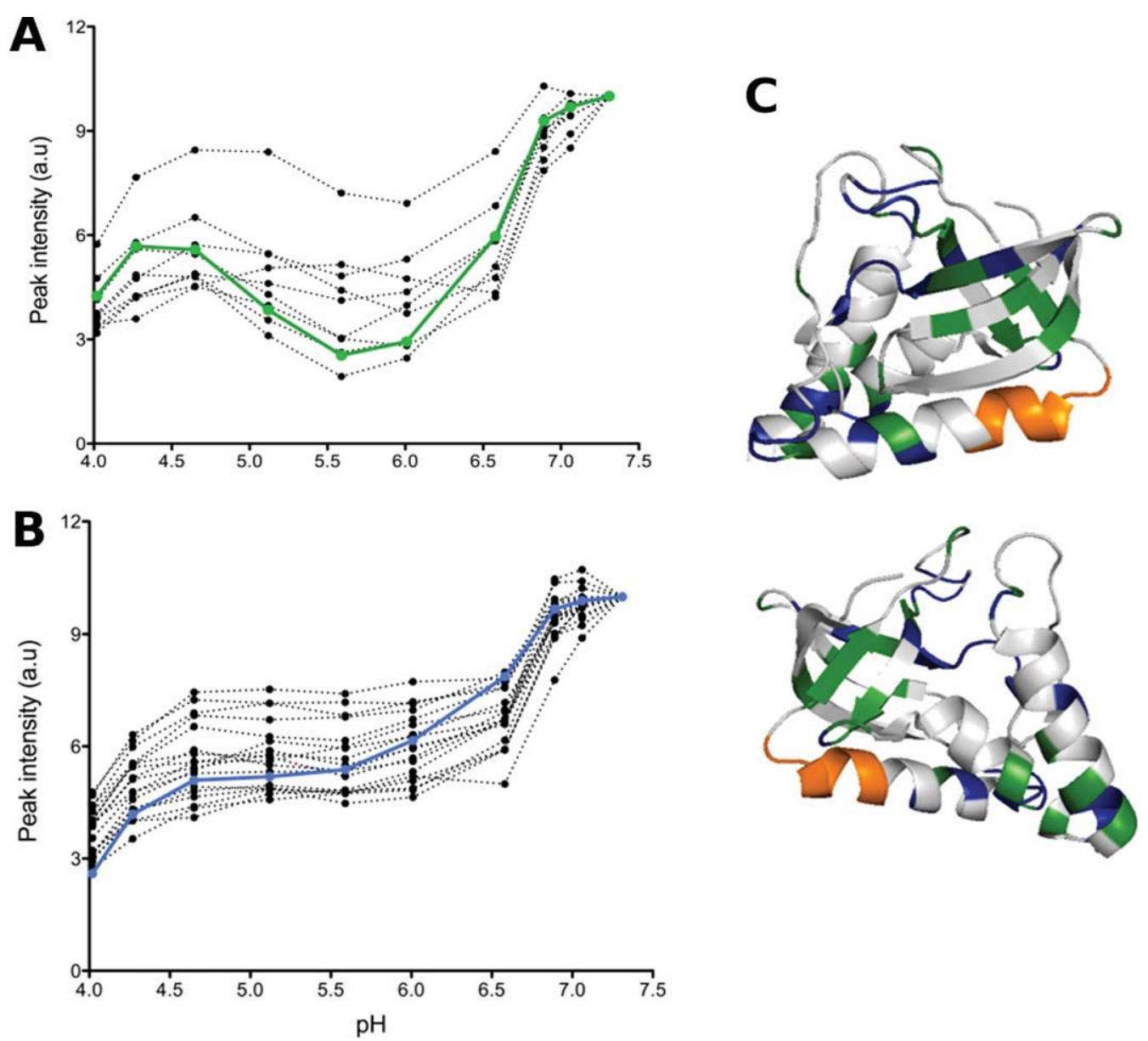

\section{Figure 1}

$\mathrm{pH}$ titrations of $\Delta+\mathrm{PHS} / \mathrm{V} 66 \mathrm{~K}$ SNase monitored with NMR spectroscopy. (A) ${ }^{1} \mathrm{H}_{-}{ }^{15} \mathrm{~N}$ HSQC peak intensity values for residues that exhibit a minimum at $\mathrm{pH}$ 5.5. (B) ${ }^{1} \mathrm{H}^{-15} \mathrm{~N}$ HSQC peak intensity values for residues that do not present a minimum at $\mathrm{pH}$ 5.5. (C) Ribbon diagram of $\Delta+$ PHS/V66K SNase with the residues that exhibit a minimum at $\mathrm{pH} 5.5$ colored in green, those that do not colored in blue, and those that are broadened beyond detection colored in orange. NMR acquisitions were carried out at $20^{\circ} \mathrm{C}$.

detectable by NMR spectroscopy and SAXS. ${ }^{21-26}$ For these reasons, use of SAXS and NMR spectroscopy to monitor consequences of pressure perturbation coupled with $\mathrm{pH}$ perturbation (to control the charged state of the internal Lys) have promise to be useful to study subtle conformational reorganization coupled to the ionization of internal groups in proteins.

\section{RESULTS}

\section{Effects of Lys-66 on conformational dynamics at ambient pressure}

${ }^{1} \mathrm{H}_{-}{ }^{15} \mathrm{~N}$ HSQC spectra of the $\Delta+\mathrm{PHS} / \mathrm{V} 66 \mathrm{~K}$ showed that when Lys-66 is charged, the resonances for backbone amides of residues surrounding Lys-66 are broadened beyond detection. ${ }^{5}$ A closer examination of the $\mathrm{pH}$ titration of the ${ }^{1} \mathrm{H}^{15}{ }^{15} \mathrm{~N}$ SQC spectrum of the $\Delta+\mathrm{PHS} / \mathrm{V} 66 \mathrm{~K}$ protein (Fig. 1) revealed a strong $\mathrm{pH}$-dependent decrease in the peak intensity, while the peak volumes remained constant, indicating conformational exchange on rather long timescales $(>\mathrm{ms})$, coupled to the ionization of Lys66. Certain residues [in blue in Fig $1(B, C)$ ] exhibited a plateau across the $\mathrm{p} K_{\mathrm{a}}$ of Lys-66, while others [in green in Fig $1(B, C)]$, particularly in the $\beta$-barrel near Lys-66, showed a minimum at the $\mathrm{p} K_{\mathrm{a}}$. This latter behavior can be interpreted as arising either from a change in dynamics, or more likely, a decrease in the conformational heterogeneity for these residues once Lys-66 is completely protonated.

NMR relaxation techniques were used to compare the dynamics of the $\Delta+$ PHS protein and its V66K variant at $\mathrm{pH}$ values above (6.5) and below (4.5) the $\mathrm{p} K_{\mathrm{a}}$ of Lys-66. The rapid, picosecond dynamics of both proteins were rather constrained, with order parameters above 0.8 across the entire structure at both $\mathrm{pH}$ values (Supporting Information Fig. S1). The relaxation parameters $\left(R^{1}, R^{2}\right.$, and heteronuclear NOE) exhibited no significant differ- 


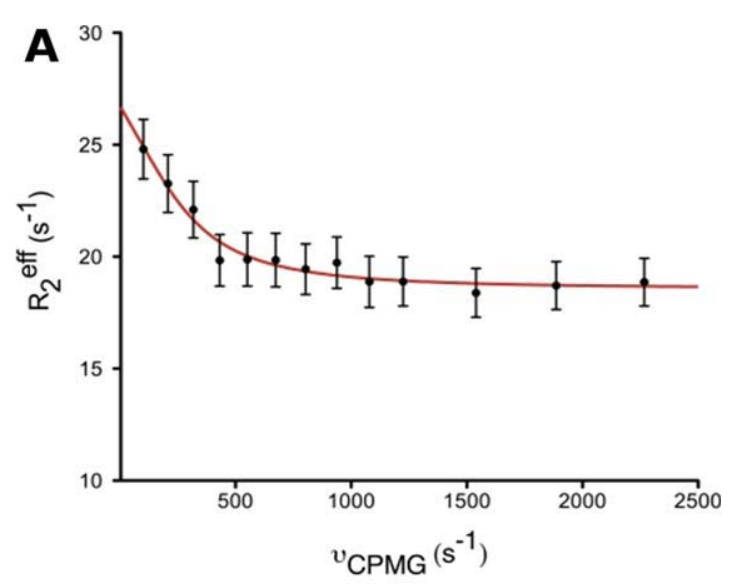

B
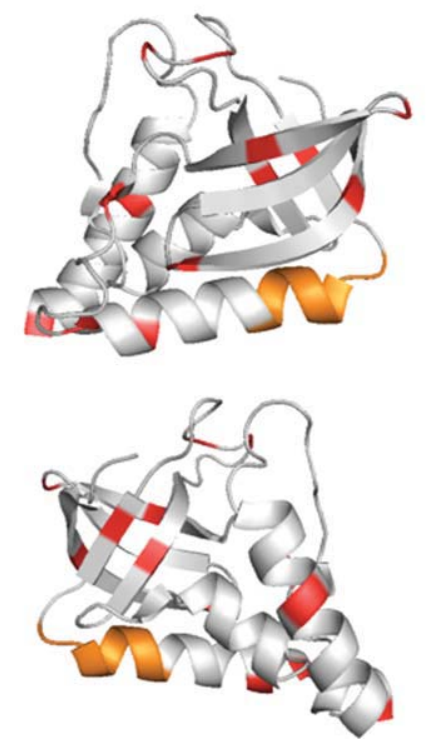

Figure 2

Results of NMR relaxation dispersion measurements on $\Delta+$ PHS/V66K at $\mathrm{pH}$ 4.5. (A) Relaxation dispersion profiles for residue 13. (B) Ribbon diagrams of $\Delta+\mathrm{PHS} / \mathrm{V} 66 \mathrm{~K}$ nuclease ${ }^{6}$ in two orientations with the residues that exhibit relaxation dispersion colored in red. Residues 62-67, whose resonances are not detected at $\mathrm{pH} 4.5$, are shown in orange. NMR acquisitions were carried out at $20^{\circ} \mathrm{C}$.

ences, demonstrating that insertion of a polar and ionizable residue into the hydrophobic core had very little effect on fast dynamics in the ps-ns range. CPMG relaxation dispersion measurements performed on the two proteins at $\mathrm{pH} 6.5$ and 4.5 revealed no evidence for conformational exchange on the $\mu$ s to ms timescale at either $\mathrm{pH}$ value for the $\Delta+$ PHS protein, consistent with its very high stability. The same was true for the $\Delta+\mathrm{PHS} /$ V66K variant at $\mathrm{pH}$ 6. However, when Lys-66 was positively charged at $\mathrm{pH} 4.5$, conformational exchange was observed at 13 positions in the $\Delta+\mathrm{PHS} / \mathrm{V} 66 \mathrm{~K}$ variant [e.g., Fig. 2(A)], with exchange times in the range of 300 $\mu s$, and with four residues apparently exchanging on the millisecond timescale (Supporting Information Table I).
The majority of the affected residues are found either in helix-1 (Y54, E57), where Lys-66 resides, or in the $\beta$-barrel of the hydrophobic core (T13, G29, T33, V74, and 192) where the side chain of Lys-66 is buried [Fig. 2(B)]. A few central residues (D19, D40, T82, and K84) between the core of the protein and helix-3, and two residues in helix-3 (K127 and S141), also appear to be perturbed by the decrease in $\mathrm{pH}$ to 4.5 .

Earlier studies showed that the V66K substitution affected the H/D exchange properties of the protein globally, even when Lys-66 is neutral. ${ }^{5}$ The ratio of the protection factors measured here between the two proteins at $\mathrm{pH} 6.5$ and 4.5 confirmed the global destabilization of the V66K variant relative to the $\Delta+\mathrm{PHS}$ background, with decreases in the protection factor of up to four orders of magnitude at both $\mathrm{pH}$ values for residues distributed throughout the protein [Figs. 3(A,B) and Supporting Information Figs. S2(A-D) and S3(A-B)]. The residues exhibiting the largest decrease in protection factor reside in helix-1, where Lys-66 is found, and in the $\beta$-barrel. Overall, the effects of the V66K substitution on the conformational dynamics of the protein probed by $\mathrm{H} / \mathrm{D}$ exchange indicate that, while both the global fluctuation and the local fluctuation are increased by the substitution, the global fluctuations are enhanced by protonation of Lys-66.

Small-angle X-ray scattering (SAXS) 27,28 experiments at atmospheric pressure were performed with $\Delta+$ PHS and its V66K variant to probe the global structural consequences of the V66K substitution and of the ionization of Lys-66, whereas at $\mathrm{pH}$ above 5.7, the $\Delta+\mathrm{PHS}$ protein and its V66K variant exhibited similar $R_{\mathrm{g}}$ values $(16.9 \pm 0.4$ and $16.6 \pm$ $0.8 \AA$ ) and pair distribution functions, at $\mathrm{pH} 4.5$, where Lys66 is charged, the V66K variant exhibited a significantly broader pair-distance distribution function and a larger $R_{\mathrm{g}}$ value $(18.1 \pm 0.5 \AA$ ) (Supporting Information Fig. S4(AC), Fig. $4(\mathrm{~A}, \mathrm{~B})$, Table I). The $\Delta+\mathrm{PHS}$ background also showed some expansion at $\mathrm{pH} 4.5(17.6 \pm 0.3 \AA)$. The Kratky plots [Fig 5(A,B)] regardless of variant or $\mathrm{pH}$ were all very similar, although not identical, with a strong maximum consistent with structured, globular proteins.

$A b$ initio modeling of the SAXS data for $\Delta+$ PHS and its $\mathrm{V} 66 \mathrm{~K}$ variant at atmospheric pressure and $\mathrm{pH} 6$ was

\section{Table I}

$\mathrm{R}_{\mathrm{g}}$ Values of $\Delta+$ PHS Nuclease and its V66K Variant under Different Conditions of $\mathrm{pH}$ and Pressure at $20^{\circ} \mathrm{C}$

\begin{tabular}{|c|c|c|}
\hline Variant & Experimental conditions & $R_{\mathrm{g}} / \AA$ \\
\hline$\Delta+\mathrm{PHS}$ & 1 bar, pH 7.0 & $16.9 \pm 0.4$ \\
\hline$\Delta+\mathrm{PHS}$ & 1 bar, $\mathrm{pH} 4.5$ & $17.6 \pm 0.3$ \\
\hline$\Delta+\mathrm{PHS}+\mathrm{V} 66 \mathrm{~K}$ & 1 bar, $\mathrm{pH} 6.0$ & $16.6 \pm 0.8$ \\
\hline$\Delta+\mathrm{PHS}+\mathrm{V} 66 \mathrm{~K}$ & 1 bar, $\mathrm{pH} 4.5$ & $18.1 \pm 0.5$ \\
\hline$\Delta+\mathrm{PHS}+\mathrm{V} 66 \mathrm{~K}$ & 3 kbar, pH 6.0 & $19.8 \pm 2.0$ \\
\hline$\Delta+\mathrm{PHS}+\mathrm{V} 66 \mathrm{~K}$ & 1 kbar, pH 4.5 & $22.8 \pm 0.7$ \\
\hline$\Delta+\mathrm{PHS}+\mathrm{V} 66 \mathrm{~K}$ & 2 kbar, pH 4.5 & $32.5 \pm 2.0$ \\
\hline$\Delta+\mathrm{PHS}+\mathrm{V} 66 \mathrm{~K}$ & 3 kbar, pH 4.5 & $30.2 \pm 2.0$ \\
\hline
\end{tabular}




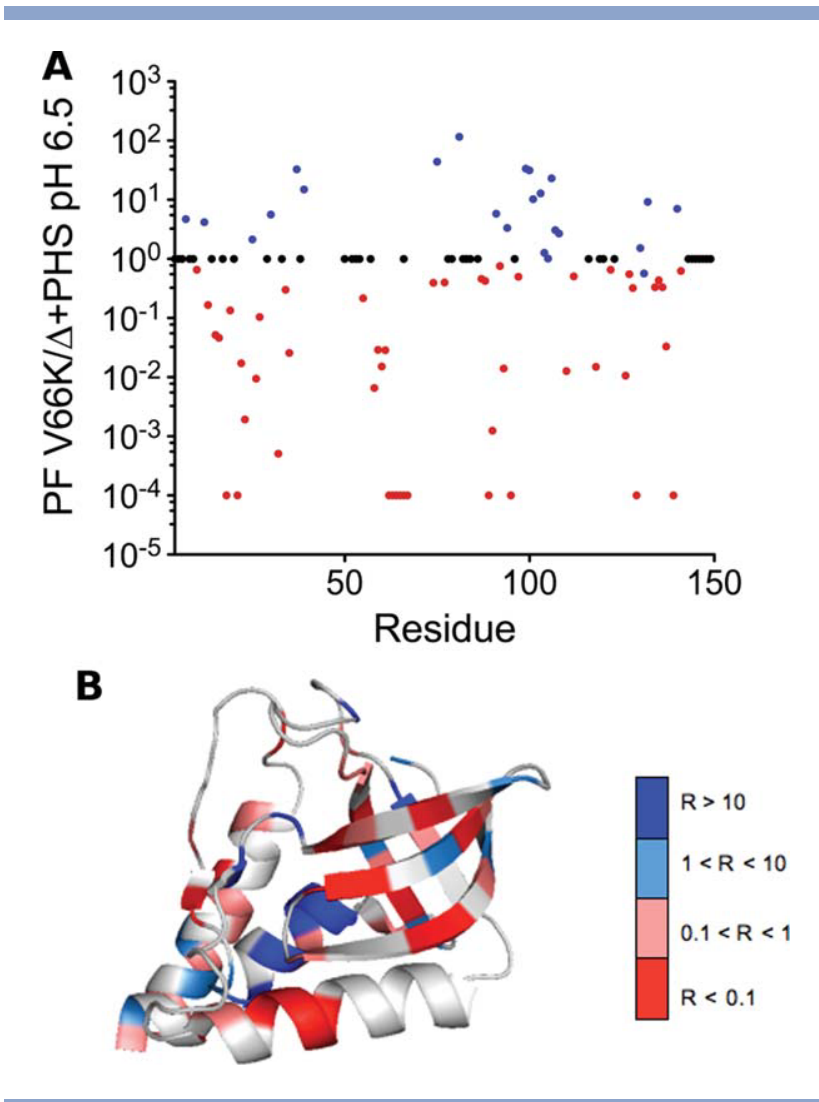

Figure 3

$\mathrm{H} / \mathrm{D}$ exchange measurements of the $\Delta+\mathrm{PHS}$ protein and its V66K

variant. (A) ratio of the exchange rates of the amide protons of $\Delta+$ PHS SNase with respect to those measured for the $\Delta+\mathrm{PHS} / \mathrm{V} 66 \mathrm{~K}$ variant at $\mathrm{pH} 6.5$; (B) ribbon diagram of $\Delta+\mathrm{PHS} / \mathrm{V} 66 \mathrm{~K}^{6}$ with the residues that exhibit faster exchange rates, as compared with the $\Delta+$ PHS background colored in pink to red from 10 -fold to 10,000 -fold faster. Blue residues are exchanged 10-fold to 100 -fold more slowly. NMR acquisitions were carried out at $20^{\circ} \mathrm{C}$. Under these conditions, the exchange occurs in the EX2 limit.

performed with the program DAMMIF. ${ }^{29}$ The most probable model from among 16 separate calculations for the $\Delta+$ PHS protein revealed a generally globular structure, with a circular indentation [Fig. 6(A,B)]. Superposition of the crystal coordinates of the $\Delta+$ PHS structure (PDB accession code 3 bdc.pdb ${ }^{4}$ ) with the ab initio model, as described in Material and Methods, yielded the best fit for the orientation shown in Figure 6(C), with helix-3 bearing tryptophan 140 (among the last residues that are usually resolved in crystal structures of SNase variants) placed just below a protrusion calculated by DAMMIF. Comparison of the scattering curve calculated from the crystal structure with the experimental profile revealed significant deviation between the two, whereas that calculated from the DAMMIF $a b$ initio model describes very well the experimental results (Supporting Information Fig. S5). Therefore, it is likely that the protrusion apparent in the $a b$ initio model corresponds to the manifestation in the DAMMIF calculation of experimental scattering from the disordered C-terminal residues 141-149, although a contribution from the disordered N-terminal residues 1-7 cannot be excluded. We
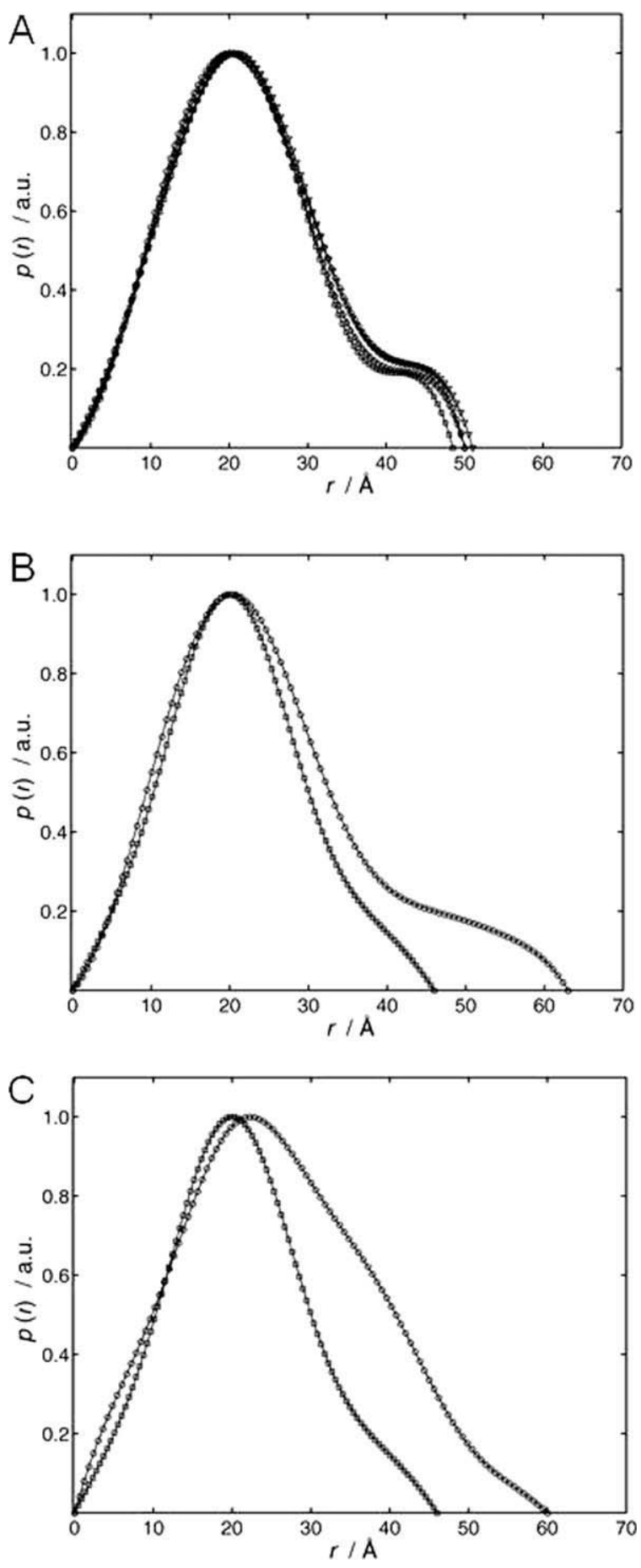

Figure 4

Normalized pair-distance distribution functions calculated from the SAXS data on $\Delta+$ PHS and its V66K variant. (A) $\Delta+$ PHS at $\mathrm{pH} 7$ and atmospheric pressure $(\square), 1 \mathrm{kbar}(\diamond), 2 \mathrm{kbar}(\bigcirc)$ and $3 \mathrm{kbar}(\nabla)$; (B) $\Delta+$ PHS/V66K at $\mathrm{pH} 4.5(\bigcirc)$ and $\mathrm{pH} 6.0(\square))$ at atmospheric pressure; (C) $\Delta+\mathrm{PHS} / \mathrm{V} 66 \mathrm{~K}$ at pH 6.0 and atmospheric pressure $(\square))$ and $3 \mathrm{kbar}(\bigcirc)$. 

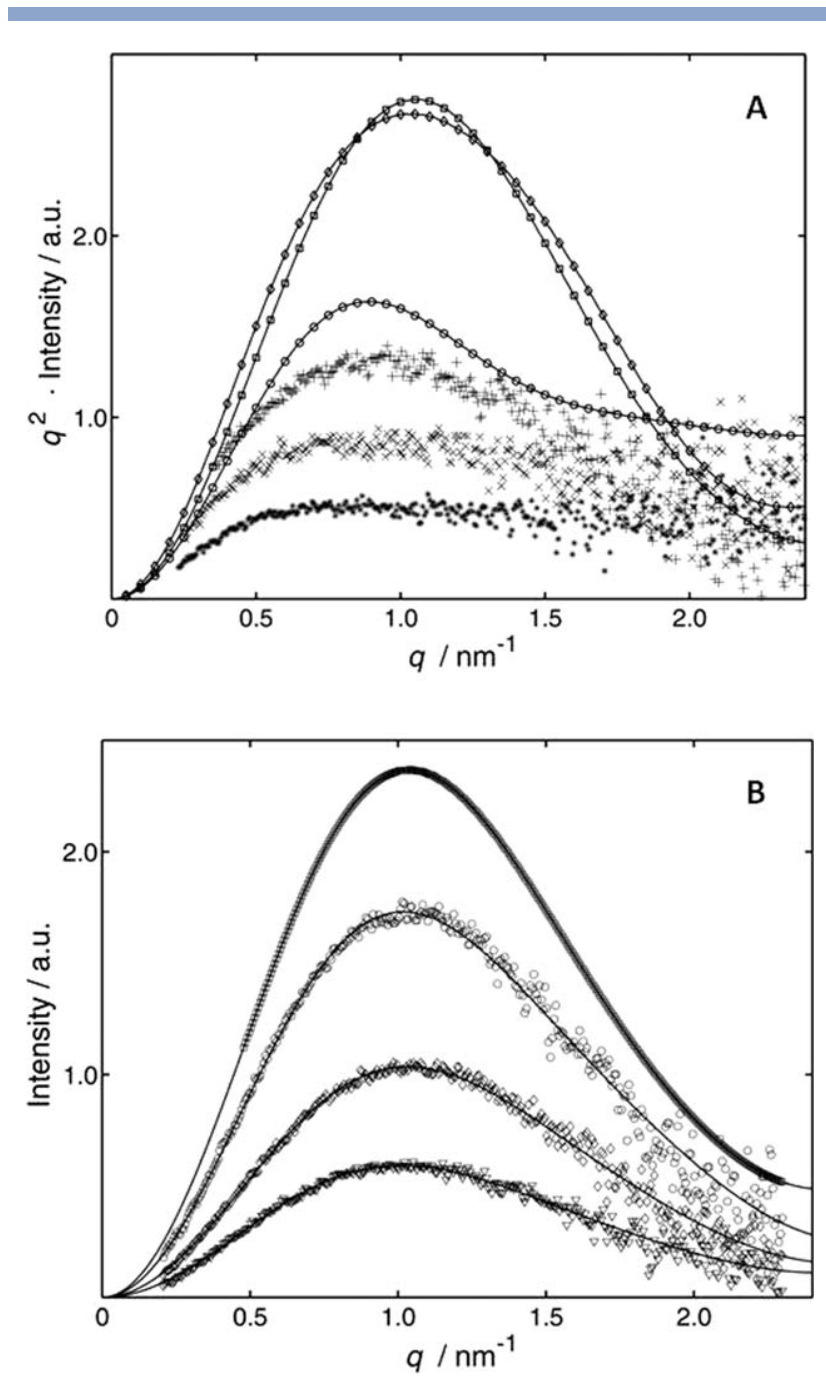

Figure 5

Kratky plots of (A) $\Delta+\mathrm{PHS} / \mathrm{V} 66 \mathrm{~K}$ SNase at: $(\square)) \mathrm{pH} 6$ and atmospheric pressure, $(\bigcirc) \mathrm{pH} 6$ and $3 \mathrm{kbar},(\diamond) \mathrm{pH} 4.5$ and atmospheric pressure, $(+) \mathrm{pH} 4.5$ and $1 \mathrm{kbar},(\times) \mathrm{pH} 4.5$ and $2 \mathrm{kbar},\left(^{*}\right) \mathrm{pH} 4.5$ and $3 \mathrm{kbar}$; (B) $\Delta+$ PHS SNase at: $(\square)) \mathrm{pH} 7$ and atmospheric pressure, $(\bigcirc) \mathrm{pH} 7$ and 1 kbar, $(\diamond) \mathrm{pH} 7$ and $2 \mathrm{kbar},(\nabla) \mathrm{pH} 7$ and $3 \mathrm{kbar}$.

note that such $a b$ initio modeling, while appropriate for stable globular structures, does not yield reliable envelopes for dynamically disordered regions, and that, therefore, this protrusion in the model should not be interpreted as a true structural envelope.

Despite the similarity in their $R_{\mathrm{g}}$ values, the $a b$ initio model for the $\Delta+$ PHS/V66K variant [Fig. 6(D,E)] appears quite different from that of the $\Delta+$ PHS reference protein. In particular, the DAMMIF modeling of the $\Delta+\mathrm{PHS} / \mathrm{V} 66 \mathrm{~K}$ variant produced two extensions that, as in the case of the single protrusion calculated for the reference protein, may also arise from disordered regions, which are more important in the $\Delta+\mathrm{PHS} / \mathrm{V} 66 \mathrm{~K}$ protein than in the reference protein. At $\mathrm{pH} 6$, close to the $\mathrm{p} K_{\mathrm{a}}$ of 5.7 of Lys-66, the SAXS data might be reporting on the superposition of multiple conformations. A slow dynamic disordering of helix 1 is supported by the H/D exchange data, which revealed substantial increases in the helix 1 exchange rates for $\Delta+\mathrm{PHS} / \mathrm{V} 66 \mathrm{~K}$ compared with the $\Delta+$ PHS reference protein. The $a b$ initio model of the V66K variant at $\mathrm{pH} 4.5$ shows a very elongated structure [Fig. 6(F)], suggesting that under conditions where Lys66 is charged, the protein populates a state in which part or all of helix-1 is separated from the core of the structure. This is consistent with the NMR results that show even faster H/D exchange, the loss of the resonances for residues $62-66$ and the broadening of resonances in the
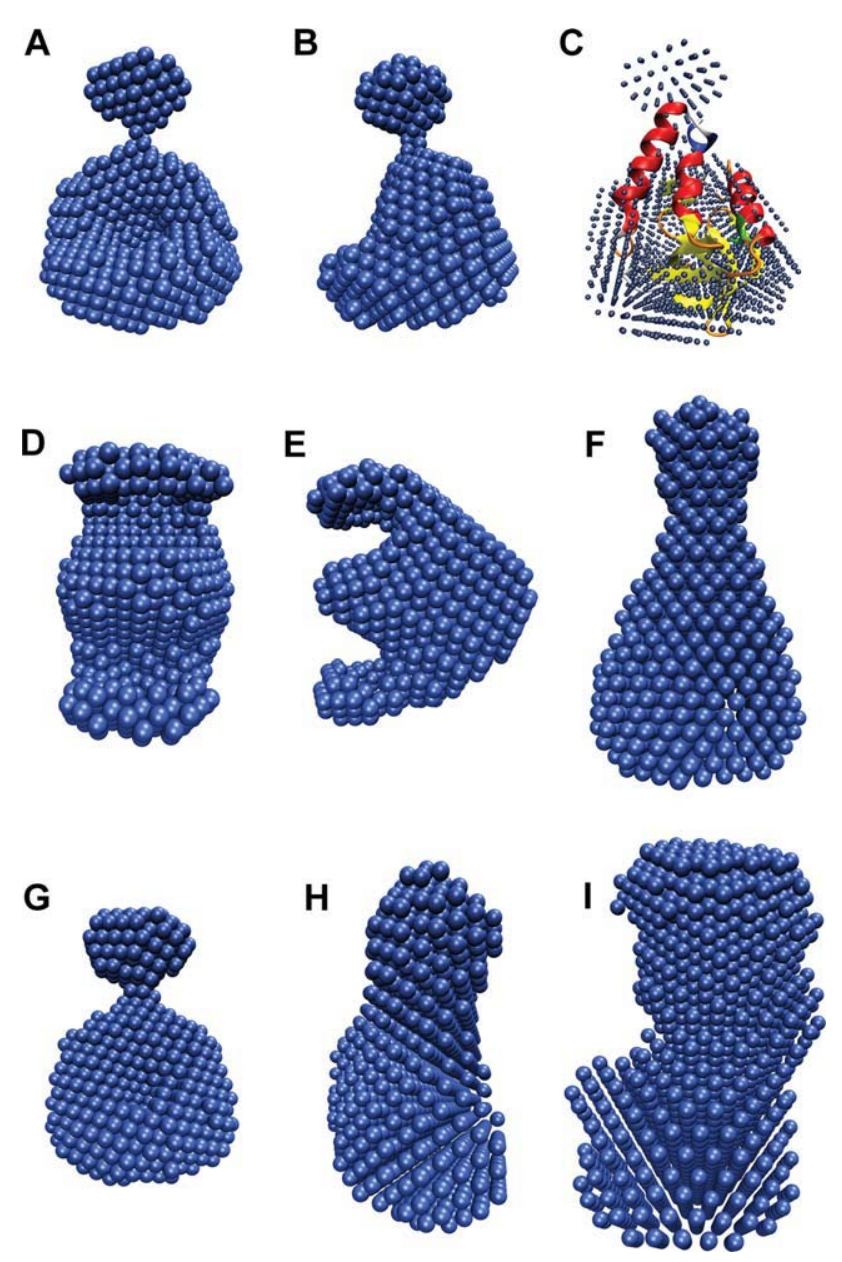

\section{Figure $\mathbf{6}$}

Results of $a b$ initio modeling of the $p(r)$ plots for $\Delta+$ PHS SNase and its V66K variants under a variety of conditions. (A) and (B) ab initio models of $\Delta+\mathrm{PHS}$ at $\mathrm{pH} 7$ and atmospheric pressure in two $90^{\circ}$ orientations, (C) the crystal structure of $\Delta+$ PHS modeled into the $a b$ initio sphere model, with $\alpha$-helices colored in red, $\beta$-strands in yellow, loops and turns in orange, position 66 in green, and the C-terminal 310 helix in blue, (D) and (E) ab initio models of $\Delta+$ PHS/V66K at atmospheric pressure and $\mathrm{pH} 6$ in two $90^{\circ}$ orientations, (F) ab initio model of $\Delta+$ PHS/V66K at atmospheric pressure and $\mathrm{pH} 4.5,(\mathbf{G}) a b$ initio model of $\Delta+\mathrm{PHS}$ at $\mathrm{pH} 7$ and $3 \mathrm{kbar},(\mathbf{H})$ ab initio model of $\Delta+$ PHS/V66K at pH 6 and $3 \mathrm{kbar}$, (I) ab initio model of $\Delta+$ PHS/V66K at $\mathrm{pH} 4.5$ and 1 kbar. 

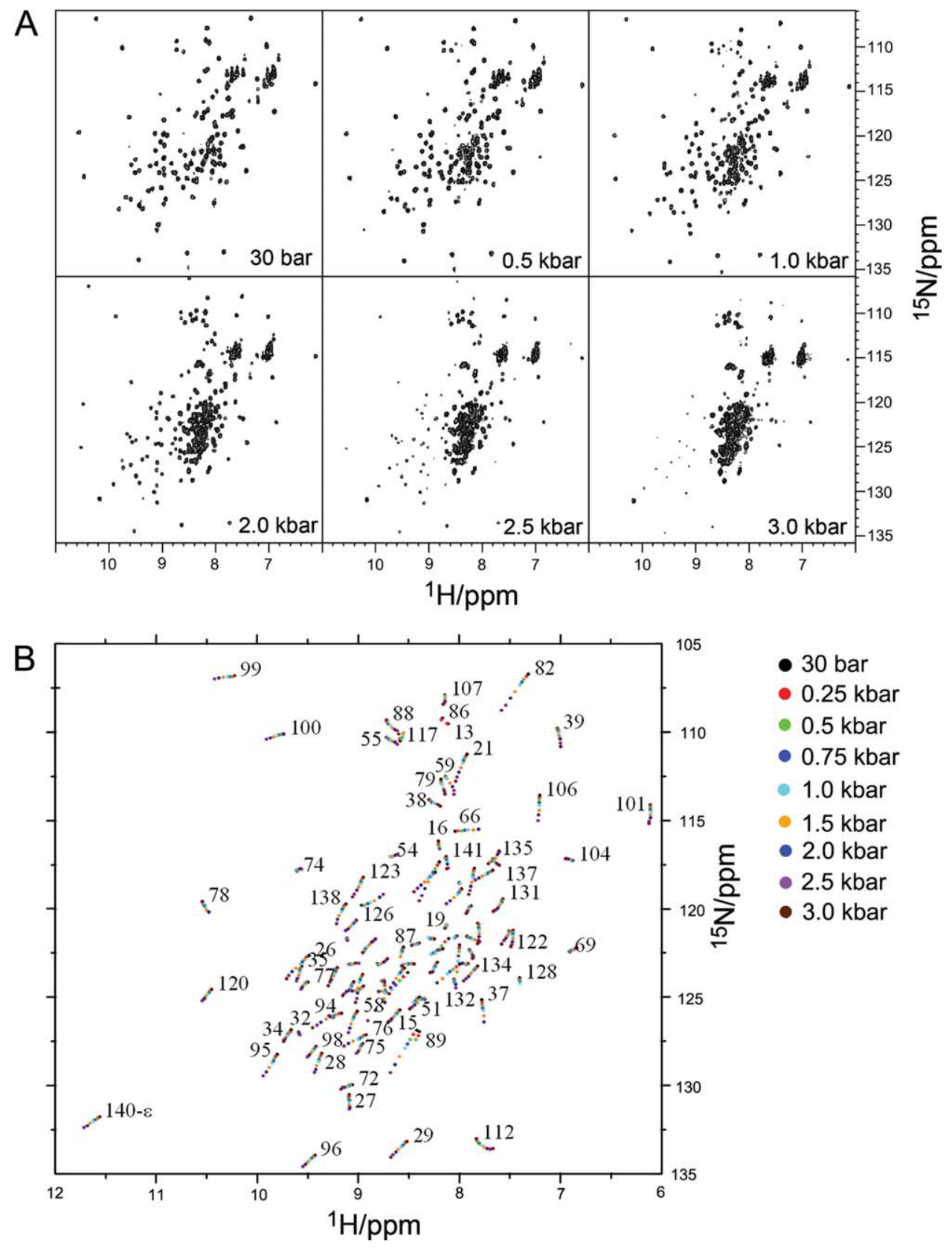

\section{Figure 7}

Pressure-dependent ${ }^{1} \mathrm{H}_{-}{ }^{15} \mathrm{~N}$ HSQC spectra of $\Delta+\mathrm{PHS} / \mathrm{V} 66 \mathrm{~K}$ SNase at $\mathrm{pH} 6.3$, NMR acquisition was carried out at $21{ }^{\circ} \mathrm{C}$. (A) Complete HSQC spectra between 30 bar and $3 \mathrm{kbar}$ as indicated. (B) Synthetic HSQC revealing the amide chemical shift variations of the folded state with pressure. Peaks shift black to yellow to purple to brown with increasing pressure between atmospheric pressure and $3 \mathrm{kbar}$.

${ }^{1} \mathrm{H}^{-15} \mathrm{~N}$ HSQC spectra of the protein when Lys-66 is charged.

\section{Effects of the neutral Lys-66 on conformational dynamics monitored with variable pressure NMR spectroscopy}

Variable pressure NMR spectroscopy was used as an additional means of assessing the effect of the V66K substi- tution on the malleability of the protein at $\mathrm{pH}$ 6.3. Under these conditions, Lys-66 is neutral and no significant differences in the protein's ps-ms dynamics were observed at atmospheric pressure as compared with the $\Delta+$ PHS reference protein. Pressure induced significant shifts in both the ${ }^{1} \mathrm{H}$ and ${ }^{15} \mathrm{~N}$ frequencies in the ${ }^{1} \mathrm{H}_{-}{ }^{15} \mathrm{~N}$ HSQC spectrum for $\Delta+\mathrm{PHS} / \mathrm{V} 66 \mathrm{~K}$ at $\mathrm{pH} 6.3$ [Figs. $7(\mathrm{~A}, \mathrm{~B})$ ] at all sites, reflecting average changes in hydrogen bond distances and in $\phi, \psi, \chi$ torsion angles. ${ }^{21-23}$ The pressure-dependent 
shifts in the HSQC resonances of the reference protein were generally smaller than those observed for the V66K variant (spectra not shown). Variations in the shifts over the entire chain reveal heterogeneous conformational fluctuation. Continuous shifts without loss of signal intensity or broadening of signals indicate that these fluctuations are rapid on the NMR time scale (fluctuations faster than $\sim \mathrm{ms}$ ). Although the majority of the shifts are linear, some are quite significantly nonlinear. The linear shifts are thought to represent the pressure-induced conformational fluctuation within the folded conformation, whereas the nonlinear shifts are attributed primarily to the increase in the population of alternative or low-lying excited state conformations. ${ }^{21-23}$ Fitting both ${ }^{1} \mathrm{H}$ and ${ }^{15} \mathrm{~N}$ shifts for the $\Delta+\mathrm{PHS}$ and $\Delta+\mathrm{PHS} / \mathrm{V} 66 \mathrm{~K}$ proteins to a second-order polynomial [Supporting Information Fig. S6(A-D)] revealed that in both the proton and nitrogen dimensions, the nonlinear coefficients for the $\Delta+$ PHS background are quite small, on the order of the average observed for BPTI, one of the least pressure sensitive proteins tested to date. $21,23,30$ The response of the $\Delta+$ PHS/V66K variant to pressure was similar to that of the reference protein over most of its structure. However, significant nonlinear pressure responses were observed in the $\Delta+\mathrm{PHS} / \mathrm{V} 66 \mathrm{~K}$ variant clustered near Lys-66 in helix- 1 and in the $\beta$-barrel (Fig. 8 $\mathrm{B}$ and $\mathrm{D}$ ). These results suggest that the V66K substitution increased significantly the pressure-induced conformational fluctuations $(<\mathrm{ms})$ into low-lying excited states and that these fluctuations involve a change in conformation in helix-1 and the $\beta$-barrel.

\section{Global unfolding of $\triangle+$ PHS/VEGK monitored by NMR spectroscopy and SAXS at high pressure}

Besides the nonlinear effect of pressure on some chemical shifts, at $\mathrm{pH} 6.3$ the $\Delta+\mathrm{PHS} / \mathrm{V} 66 \mathrm{~K}$ variant underwent major spectral changes in the ${ }^{1} \mathrm{H}_{-}{ }^{15} \mathrm{~N}$ HSQC as pressure increased to $3 \mathrm{kbar}$ [Fig 7(A)]. The well-dispersed resonances of the folded state reversibly decreased in intensity while those less resolved central peaks corresponding to the unfolded protein increased in intensity, clearly showing that the entire polypeptide chain became unfolded, in complete agreement with fluorescence experiments under similar conditions. ${ }^{14}$ The observation of separate signals for the folded and unfolded conformers reveals that global unfolding is slow on the NMR time scale $(>\mathrm{ms})$. It was possible to follow the loss of peak intensity over the entire pressure range for 47 of the 138 residues of the protein. Plots of peak intensity versus pressure for these residues were analyzed (Supporting Information Fig. S7) to obtain residue specific values of the apparent unfolding free energy $\left(\Delta G_{\mathrm{u}}\right)$ and volume change on unfolding $\left(\Delta V_{\mathrm{u}}\right)$. The average $\Delta V_{\mathrm{u}}$ calculated from the values of all the residues was $-67.7 \pm 16 \mathrm{~mL} \mathrm{~mol}^{-1}$, and the average $\Delta G_{\mathrm{u}}$ was $3.4 \pm$ $0.8 \mathrm{kcal} \mathrm{mol}^{-1}$, in agreement the values of $\Delta V_{\mathrm{u}}(-60 \pm 6 \mathrm{~mL}$ $\left.\mathrm{mol}^{-1}\right)$ and $\Delta G_{\mathrm{u}}\left(3.0 \pm 0.3 \mathrm{kcal} \mathrm{mol}^{-1}\right)$ obtained previously
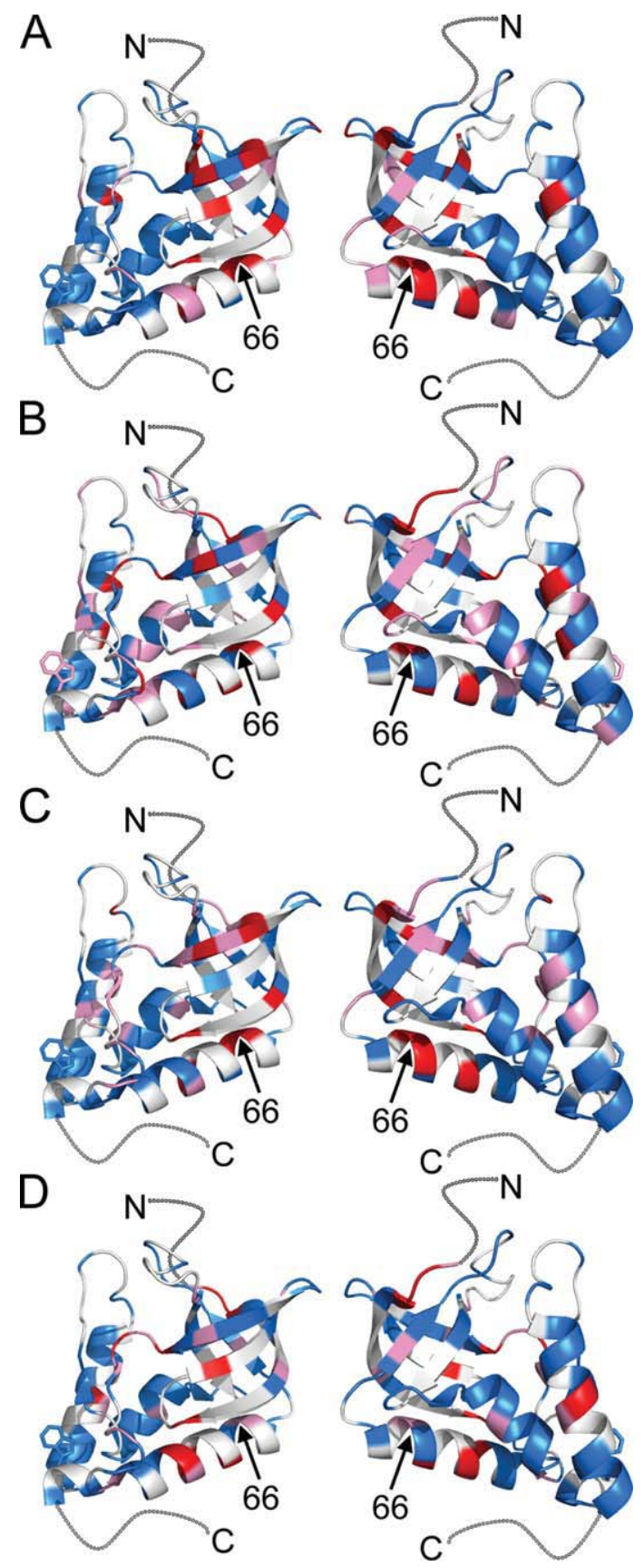

Figure 8

Ribbon diagrams of $\Delta+\mathrm{PHS}^{4}$ showing residues in $\Delta+\mathrm{PHS} / \mathrm{V} 66 \mathrm{~K}$ that at $\mathrm{pH} 6.3$ exhibit large 1st $(\mathrm{A}, \mathrm{C})$ or $2 \mathrm{nd}(\mathrm{B}, \mathrm{D})$ order pressure coefficients for peak position for either ${ }^{1} \mathrm{H}(\mathrm{A}, \mathrm{B})$ or ${ }^{15} \mathrm{~N}(\mathrm{C}, \mathrm{D})$ resonances, colored in red ( $>2$ standard deviations) purple $(>1$ standard deviation) and blue ( $<1$ standard deviation). White indicates no data because of signal overlap or missing assignments. Two different orientations are shown for each case for clarity.

for this variant at $\mathrm{pH} 6.0$ from analysis of pressure-induced fluorescence changes. ${ }^{14}$

The effect of pressure on the global structure of the reference $\Delta+$ PHS protein and its V66K variant was also 
characterized by SAXS measurements at high pressure [Supporting Information Fig. S4(B)]. Ab initio modeling of the $p(r)$ functions of the reference protein [Fig. 4(A)] revealed a very limited change in shape at $3 \mathrm{kbar}$, which modeled only as an attenuation of the circular indentation [Fig. $6(\mathrm{G})$ ] in the globular structure. In contrast, the major change in conformation of the $\Delta+\mathrm{PHS} / \mathrm{V} 66 \mathrm{~K}$ variant, observed by high-pressure NMR and fluorescence, was confirmed by SAXS. The $p(r)$ for this variant at $\mathrm{pH}$ 6 [Fig. 4(C)] broadened and the $R_{\mathrm{g}}$ increased from 16.6 \pm 0.4 to $19.8 \pm 2.0 \AA$ (Table I), indicating expansion of the chain relative to the native state. However, this value for the $R_{\mathrm{g}}$ of the pressure-unfolded $\Delta+\mathrm{PHS} / \mathrm{V} 66 \mathrm{~K}$ variant is much smaller than the value of $35 \AA$ obtained previously for the high-pressure unfolding of the true wildtype form of SNase ${ }^{17}$ under similar conditions ( $\mathrm{pH}$ 5.5). Hence, even with the V66K substitution, the pressure unfolded state of the $\Delta+$ PHS variant remained much less expanded than that of the wild-type protein. The Kratky plot obtained from the scattering data on the V66K variant at $3 \mathrm{kbar}$ and at $\mathrm{pH} 6$ [Fig. 5(A)] exhibited a small maximum reflecting some residual globular structure in this unfolded state. Ab initio modeling of the scattering curves under these conditions [Fig. 6(H)] was consistent with a significantly expanded structure relative to atmospheric pressure. Furthermore, the SAXS data show that ionization of Lys-66 (at $\mathrm{pH}$ 4.5) shifted the unfolding transition to lower pressure which was complete by $2 \mathrm{kbar}$, as observed previously by fluorescence. ${ }^{14}$ The radius of gyration at $\mathrm{pH} 4.5$ and 2 kbar $(\sim 32 \AA$, Table I), was close to the value of $35 \AA^{17}$ observed for pressure denatured WT SNase, yet it was not as large as for chemically denatured wild-type SNase $\left(R_{\mathrm{g}}=37.2 \pm\right.$ $1.2 \AA)^{31}$ or for the temperature denatured WT protein $\left(R_{\mathrm{g}}=45 \pm 2 \AA\right) .{ }^{17}$ Kratky plots [Fig. 5(A)] of the highpressure SAXS profiles (2 and 3 kbar) at $\mathrm{pH} 4.5$ showed no maximum, indicating that under these conditions the protein behaved like a random polymer. Likewise, the $a b$ initio model [Fig. 6(I)] was consistent with a highly expanded chain. Because Lys-66 in the $\Delta+$ PHS/V66K variant is charged in the unfolded state at $\mathrm{pH} 6$ as well

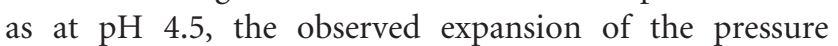
unfolded state at low $\mathrm{pH}$ must arise from general destabilization of residual interactions arising from increased electrostatic repulsion in the unfolded state as carboxylic groups begin to become neutralized.

\section{DISCUSSION AND CONCLUSIONS}

Previous studies of the $\Delta+$ PHS protein and its V66K variant with NMR spectroscopy have shown that the response of the protein to the ionization of Lys-66 is limited and localized to the vicinity of the side chain of the lysine. ${ }^{5}$ Because structural and dynamic consequences of the presence and ionization of the internal Lys-66 are affected by the volume differences between Val and Lys, and by the differences in hydration of Lys in water and Lys inside a protein, the application of high-hydrostatic pressure was expected to shed insight into the structural determinants of the properties of the internal Lys-66 and the response of the protein to the presence of a charged group in the mid of its hydrophobic core.

The present studies at atmospheric pressure show that at $\mathrm{pH}$ values close to the $\mathrm{p} K_{\mathrm{a}}$ value of Lys-66, the protein exists in dynamic equilibrium on relatively slow timescales between two or more conformations. The maximal loss of intensity at the $\mathrm{p} K_{\mathrm{a}}$ of Lys-66 suggests that a few residues in the barrel are exchanged broadened on a rather slow timescale $(>\mathrm{ms}$ ) owing to a mixed population of protonated and unprotonated Lys-66. A dynamic equilibrium of the side chain between a buried position, where it is neutral and one less buried, where it is charged and more hydrated, is compatible with this slow timescale, but so is an equilibrium between ordered and disordered backbone for the segment 62 to 67. Interestingly, the fast (ps-ns) relaxation of the protein was unperturbed by the V66K substitution or by the ionization of Lys-66, supporting the former interpretation. A $b$ initio modeling of SAXS data also suggested the coexistence of several conformations near the $\mathrm{p} K_{\mathrm{a}}$, one native, and one or more conformations in dynamic equilibrium, probably involving some or all of helix-1, which becomes more exposed to solvent and maybe also more disorganized on complete protonation of Lys-66 at $\mathrm{pH}$ values below 5.7.

Application of moderate pressures to the $\Delta+\mathrm{PHS} / \mathrm{V} 66 \mathrm{~K}$ variant at $\mathrm{pH}$ just above the $\mathrm{p} K_{\mathrm{a}}$ of Lys-66 and below the pressure unfolding limit allowed observation of the effect of pressure on the ${ }^{15} \mathrm{~N}$ and ${ }^{1} \mathrm{H}$ resonances arising from the folded state manifold. These experiments revealed that only residues in the region adjacent to Lys-66 (helix 1 and $\beta$-barrel) showed significant nonlinear pressure profiles of their chemical shifts, indicative of the pressure-induced population of alternate, more open conformations with a smaller specific volume due to increased hydration and loss of cavities. It is of interest that the residues exhibiting the nonlinear pressure effect are found in the same region of the protein, around Lys-66, as those that are affected on protonation of this residue. Although the ensemble of lowlying excited conformations populated by protonation of Lys-66 are surely distinct from those accessed by application of pressure to this variant above the $\mathrm{p} K_{\mathrm{a}}$ of Lys-66, they are likely to share some of the same features, and clearly involve dynamic disordering of the same regions. The internal cavity where Lys-66 resides is smaller in the V66K variant than in the true wild-type or $\Delta+$ PHS reference protein, then, the variant should be less pressure sensitive. In contrast, hydration of the charged lysine residue should decrease the molar volume; this could account for the pressure-induced conformational changes. The two different types of perturbation that were applied (pressure and $\mathrm{pH}$ ), operate through fundamentally different physical 
principles, but both reveal local plasticity in the V66K variant that were not apparent under standard conditions.

Application of hydrostatic pressures larger than $2 \mathrm{kbar}$ results in the unfolding of the $\Delta+\mathrm{PHS} / \mathrm{V} 66 \mathrm{~K}$ protein. The NMR data are consistent with a concerted two state global unfolding. Interestingly, the SAXS data revealed that the pressure-unfolded form of the protein is significantly more compact than that of wild-type SNase under comparable conditions of high pressure, $\mathrm{pH}$ and temperature, ${ }^{14}$ despite the fact that the calculated volume changes and tryptophan fluorescence properties are nearly identical. The more condensed chain at high pressure for the unfolded state of the $\Delta+\mathrm{PHS} / \mathrm{V} 66 \mathrm{~K}$ variant could arise from residual stabilizing interactions in the hydrophobic core that are inherent to the $\Delta+$ PHS reference protein (as compared with the true wild-type form of SNase). The differences in compactness between the unfolded states of the variants of SNase reported here and previously 17,18 may be less apparent using chemical denaturants because the physical basis for chemical denaturation involves interaction of the denaturant with the polypeptide chain, and, hence, denaturants, unlike pressure, intrinsically favor expanded structures. In contrast, pressure acts simply to reduce volume, and, hence, residual interactions that do not contribute to volume effects are often preserved at high pressure. ${ }^{32-35}$ Apparently, further disruption of the core in the case of wild-type SNase compared with the compact denatured state populated by the $\Delta+\mathrm{PHS} / \mathrm{V} 66 \mathrm{~K}$ protein is not associated with a further decrease in volume. The differences observed in chain compaction in the pressure unfolded ensemble for the V66K variant compared with wild-type SNase suggests that pressure may reveal intrinsic sequencedependent characteristics of the unfolded state that are obscured using harsher, chemical perturbation.

The detailed examination of the structural and dynamic consequences of the presence and ionization of groups in the hydrophobic core of a protein has revealed that the response of the protein can be rather subtle. The comparison of site-specific structural and dynamic information obtained from NMR with the global information about protein shape and chain condensation available from SAXS has confirmed that there is a change, that the change is localized to the region in the vicinity of Lys-66, but that, surprisingly, most of the protein remains intact after the ionization of the internal group. By using coupled changes in hydrostatic pressure and $\mathrm{pH}$ to perturb the system, we were able to examine the effect of the substitution on the local malleability of the structure, as well as the surprising robustness of the folded ensemble. These important observations confirm that the apparent dielectric constant needed to reproduce the $\mathrm{p} K_{\mathrm{a}}$ of Lys-66 with continuum electrostatics methods is high because the subtle, dynamic structural reorganization coupled to the ionization of the internal Lys needs to be accounted for implicitly in this dielectric constant. ${ }^{6,8,9} \mathrm{New}$ microscopic methods that account explicitly for conformational reorganization coupled to the ionization of internal groups will be required for accurate calculation of the $\mathrm{p} K_{\mathrm{a}}$ of Lys-66 and for understanding the structural basis of function in proteins that depend on internal ionizable groups to perform energy transduction. ${ }^{36-38}$

\section{MATERIALS AND METHODS}

\section{Protein preparation}

The $\Delta+$ PHS variant of SNase and the $\Delta+$ PHS/V66K were prepared as described previously. ${ }^{7}$ Uniform ${ }^{15} \mathrm{~N}$ labeling was obtained from over-expression of recombinant protein in $E$.coli grown in M9 medium containing ${ }^{15} \mathrm{NH}_{4} \mathrm{Cl}$ as the sole nitrogen source. After purification, proteins were dialyzed against $1 M \mathrm{KCl}$, then against water before lyophilization.

\section{NMR relaxation dispersion-HD exchange and pH titrations}

Protein samples were dissolved at $1 \mathrm{~m} M$ concentration in $600 \mu \mathrm{L}$ of Tris $10 \mathrm{mM}$ buffer (for data at $\mathrm{pH}$ 6.5) or in Acetate $25 \mathrm{mM}$ buffer with $150 \mathrm{mM} \mathrm{NaCl}$ (for data at $\mathrm{pH} 4.5$ ). $5 \%$ of $\mathrm{D}_{2} \mathrm{O}$ was then added for the lock procedure. Temperature was carefully adjusted to $20^{\circ} \mathrm{C}$ using a calibration sample ( $80 \%$ glycol in $d_{6}$-DMSO). For $\mathrm{pH}$ titration adjustments of $\mathrm{pH}$ values to 7.1, 6.9, 6.6, 6.0, 5.6, $5.1,4.6,4.3$, and 4.0 was done by small additions of $\mathrm{HCl}$ and $\mathrm{NaOH}$ solutions: ${ }^{1} \mathrm{H}$ and ${ }^{15} \mathrm{~N}$ chemical shift variations were measured on HSQC spectra recorded at 600 $\mathrm{MHz}$ on $\Delta+\mathrm{PHS}$ and $\Delta+\mathrm{PHS} / \mathrm{V} 66 \mathrm{~K}{ }^{15} \mathrm{~N}$-labeled samples, on a Bruker Avance III spectrometer.

Heteronuclear relaxation parameters were obtained with $\Delta+\mathrm{PHS}$ and $\Delta+\mathrm{PHS} / \mathrm{V} 66 \mathrm{~K}$ samples uniformly enriched in ${ }^{15} \mathrm{~N}$ at $\mathrm{pH} 4.5$ on Bruker Avance III spectrometers operating at three different magnetic fields corresponding to proton frequencies of 400,500, and 600 $\mathrm{MHz}$. Heteronuclear longitudinal relaxation rates $\left(R_{1}\right)$ measurements were performed at these three fields using 10 inversion-recovery experiments with a relaxation delay of 18 to $1206 \mathrm{~ms}$. Heteronuclear transversal relaxation rates $\left(R_{2}\right)$ were obtained at $500 \mathrm{MHz}$ using $10 \mathrm{CPMG}$ experiments with a relaxation delay of 16 to $192 \mathrm{~ms}$. Heteronuclear NOE values were calculated from two experiments performed at $500 \mathrm{MHz}$, one collected with and one without proton presaturation. The final five relaxation rates measured for each individual amide vectors were converted into five spectral density values following the fast spectral density mapping strategy. ${ }^{39}$ The corresponding spectral density functions were then fitted by a "model free" approach, using the DYNAMOF software, ${ }^{40}$ allowing calculation of the order parameter and specific correlation times for each residue.

CPMG dispersion relaxation experiments were performed at $500 \mathrm{MHz}$ using 10 frequencies from 101.874 to $2267.274 \mathrm{~s}^{-1}$ and a $\tau_{\mathrm{CPMG}}$ delay of $40 \mathrm{~ms}$. The sample 
preparation was the same as for the heteronuclear relaxation experiments. The $\tau_{\mathrm{ex}}$ and $R_{\mathrm{ex}}$ values were calculated by fitting the $R_{2}{ }^{\text {eff }}$ decay curve of each residue using a fast exchange limit expression (Meiboom-Gill model).

\section{H/D exchange}

For $\mathrm{H} / \mathrm{D}$ exchange experiments, samples were dissolved in $\mathrm{D}_{2} \mathrm{O}$ at a concentration of $1 \mathrm{mM}$ after lyophilization. $\left[{ }^{1} \mathrm{H}-{ }^{15} \mathrm{~N}\right]-\mathrm{HSQC}$ spectra were recorded at either 500 or 600 $\mathrm{MHz}$. The time series used for each set of experiments ranged from $5 \mathrm{mn}$ to $120 \mathrm{~h}(\Delta+\mathrm{PHS} \mathrm{pH} 6.5), 5 \mathrm{mn}$ to $136 \mathrm{~h}$ $(\Delta+\mathrm{PHS} / \mathrm{V} 66 \mathrm{~K} \mathrm{pH}$ 6.5), $20 \mathrm{mn}$ to $148 \mathrm{~h}(\Delta+\mathrm{PHS} \mathrm{pH} 4.5)$ and $20 \mathrm{mn}$ to $96 \mathrm{~h}(\Delta+\mathrm{PHS} / \mathrm{V} 66 \mathrm{~K} \mathrm{pH} 4.5)$. Amide proton protection factors ${ }^{41}$ were calculated from the observed exchange rates $\left(k_{\mathrm{ex}}\right)$ obtained from the time dependence of the peaks intensities using an exponential decay.

\section{High pressure NMR}

For the high pressure NMR experiments, protein samples were prepared with $20 \mathrm{mM} \mathrm{d}$-Tris- $\mathrm{HCl}$ buffer. Protein concentration and sample $\mathrm{pH}$ were $1.2 \mathrm{mM}$ and $\mathrm{pH} 6.3$, respectively. NMR data was collected at $21{ }^{\circ} \mathrm{C}$. Spectral assignments of ${ }^{1} \mathrm{H}$ and ${ }^{15} \mathrm{~N}$ cross-peaks for the $\Delta+$ PHS and $\Delta+$ PHS/V66K proteins have been done previously. ${ }^{1}$ High-pressure NMR experiments were performed on a Bruker DRX 800 spectrometer combined with the on-line high pressure NMR cell technique as previously described. ${ }^{42}$ At all pressures, ${ }^{1} \mathrm{H}$ chemical shifts were directly referenced to the methyl resonance of DSS, while ${ }^{15} \mathrm{~N}$ chemical shifts were referenced indirectly to the absolute frequency ratios ${ }^{15} \mathrm{~N} /{ }^{1} \mathrm{H}=$ 0.101329118 .

Under physiological conditions, the protein can be considered to be nearly fully folded in conformer $N$, giving NMR signal intensity $I_{0}$ for site $i$. When with increasing pressure either local or global unfolding takes the protein into another conformer $U$, the original signal intensity $I_{0}$ for site $i$ decreases to a final value, $I_{\mathrm{f}}$, which at each measured pressure is $I_{\mathrm{p}}$. The decrease in the intensity, $I_{0}-I_{\mathrm{p}}$, divided by the intensity $I_{\mathrm{p}}$ represents the equilibrium constant $[\mathrm{U}] /[\mathrm{N}]$ at site $i$ :

$$
K_{\mathrm{i}}(p)=[\mathrm{U}] /[\mathrm{N}]=\left(I_{0}-I_{\mathrm{p}}\right) /\left(I_{\mathrm{p}}-I_{\mathrm{f}}\right)
$$

In actual application, $I_{\mathrm{p}}$ represents individual cross peak intensities in two-dimensional HSQC spectra. The Gibbs free energy difference $\Delta G(p)$ between the two conformers is expressed as a function of pressure $p$ by Eq. (2), under the assumption of negligible changes of differential compressibility with pressure between the two conformers.

$$
\Delta G(p)=-R T \ln K=\Delta G^{0}+\Delta V^{0}\left(p-p^{0}\right)
$$

Here, $R$ is the gas constant, $T$ is the absolute temperature, $K(p)$ is the equilibrium constant, and $\Delta G(p)$ and
$\Delta G^{0}$ are the Gibbs free energy differences at pressure $p$ and $p_{0}(=1$ bar $)$, respectively. $\Delta V^{0}$ is the partial molar volume difference between the two conformers at pressure $p_{0}(=1$ bar $)$. The experimentally measured values of $I_{\mathrm{p}}$ were fitted to Eqs. (1) and (2), for the parameters, $\Delta G^{0}$ and $\Delta V^{0}$ and the asymptotic values $I_{0}$ and $I_{\mathrm{f}}$ using the program, Bioeqs. ${ }^{43,44}$

\section{SAXS sample preparation}

For the SAXS experiments, protein solutions were prepared immediately before the measurements were performed. To avoid pressure-induced changes of solution $\mathrm{pH}, 25 \mathrm{mM}$ Tris buffer was used in the $\mathrm{pH}$ range of 6-7. respectively. ${ }^{45}$ At $\mathrm{pH} 4.5$, these buffers do not keep the $\mathrm{pH}$ constant. Thus, a $15 \mathrm{mM} \mathrm{Na}$ acetate buffer solution was used instead. All buffers were prepared with deionized water. The $\mathrm{pH}$ was adjusted using concentrated $6 \mathrm{~N}$ $\mathrm{HCl}$. The protein concentration in the solutions was 3.5$5.0 \mathrm{mg} \mathrm{mL} \mathrm{mL}^{-1}$. At this concentration, the solution is diluted enough so that the single scattering approximation is valid. ${ }^{46}$ However, the scattering signal is still intense enough.

\section{SAXS experiments}

SAXS experiments were performed at beamline BL9 of DELTA (TU Dortmund, Germany) ${ }^{47}$ and at beamline BW4 of HASYLAB (DESY, Hamburg, Germany) ${ }^{48}$. To investigate the SAXS signal of the protein solutions under high pressure, a special sample cell using two flat diamond windows was used. ${ }^{49} \mathrm{~A}$ range of 1 bar to $3 \mathrm{kbar}$ was covered in the experiments. Owing to the different brilliances at the various beamlines of the synchrotron facilities used, the exposure time of the protein solution with X-rays was adapted to the experimental conditions. At BW4 $(\lambda=1.3808 \AA)$, using the Pilatus $300 \mathrm{~K}$ detector, a $q$-range 0.2 to $2.8 \mathrm{~nm}^{-1}$ could be covered. The exposure time was $20 \mathrm{~min}$. A quite similar exposure time was used at BL9 by using a MAR345 image plate detector. A wavelength of $\lambda=1.239 \AA$ allowed covering a $q$-range of 0.3 to $3.5 \mathrm{~nm}^{-1}$.

\section{SAXS data analysis}

In the case of highly diluted protein solutions, the SAXS signal $I(q)$ is the spherically averaged squared modulus of the Fourier transform of the protein electron density, $\rho(\vec{r})^{50}$

$$
I(q)=n \cdot P(q)=n \cdot\left\langle\left[\int_{V o l} \rho(\vec{r}) \cdot e^{i \vec{q} \vec{r}} d^{3} r\right]^{2}\right\rangle_{\Omega},
$$

where $n$ denotes the protein's number density, $P(q)$ the protein's form factor and $\langle\cdot\rangle_{\Omega}$ denotes the spherical average. The wavevector transfer $q=(4 \pi / \lambda) \sin \theta$ is a function of the scattering angle $2 \theta$ and the incident 
wavelength $\lambda$. For small $q$ values, the scattered intensity can be expressed by the so-called Guinier approximation:

$$
I(q)=I(0) \cdot e^{-R_{g}^{2} \cdot q^{2} / 3} .
$$

The radius of gyration $R_{\mathrm{g}}$, describing the characteristic size of a scattering object, is given as: 50

$$
\begin{aligned}
R_{g}^{2} & =\int_{V^{\circ} l} \rho(\vec{r}) \cdot r^{2} d^{3} r / \int_{V^{\prime o l}} \rho(\vec{r}) d^{3} r \\
& =\int_{0}^{D_{\max }} p(r) r^{2} d r / 2 \int_{0}^{D_{\max }} p(r) d r
\end{aligned}
$$

where $D_{\max }$ is the maximum dimension of the protein and $p(r)$ is the so-called pair-distance distribution function, characterizing the shape and size of the particle. The Guinier approximation is valid for $q$-values up to $q_{\max } \leq 1.3 / R_{\mathrm{g}} \cdot 27$

After azimuthally averaging of the SAXS spectra, the scattering signals were normalized and corrected for solvent and background scattering by subtracting the scattering curve of the corresponding pure buffer solution. To obtain the radii of gyration, the low $q$-range showing a linear curve shape in the $q^{2}$ versus log $[I(q)]$ representation was fitted according to Guinier's approximation. The pair-distance distribution functions were calculated by fitting the scattering data using the program GNOM. ${ }^{51}$ To reveal if the proteins are folded or denatured, SAXS curves are shown in the so-called Kratky plot, that is, $q$ versus $q^{2} I(q)$. In the case of a globular, folded protein, the scattering curve exhibits a distinct maximum, whereas in the case of an unfolded polypeptide, the curve displays a flat plateau. ${ }^{51}$ For each structure, 16 independent $a b$ initio calculations were started using the program DAMMIF. ${ }^{29}$ The resulting 16 ab initio structures were aligned by using DAMAVER to build the "most probable" model for each protein and the crystal structures were fit into the $a b$ initio models using the same program. 52,53

\section{REFERENCES}

1. Stites WE, Gittis AG, Lattman EE, Shortle D. In a staphylococcal nuclease mutant the side-chain of a lysine replacing valine 66 is fully buried in the hydrophobic core. J Mol Biol 1991;221:7-14.

2. Baran KL, Chimenti MS, Schlessman JL, Fitch CA, Herbst KJ, Garcia-Moreno BE. Electrostatic effects in a network of polar and ionizable groups in staphylococcal nuclease. J Mol Biol 2008;379:10451062.

3. Garcia-Moreno B, Dwyer JJ, Gittis AG, Lattman EE, Spencer DS, Stites WE. Experimental measurement of the effective dielectric in the hydrophobic core of a protein. Biophys Chem 1997;64:211-224.

4. Castaneda CA, Fitch CA, Majumdar A, Khangulov V, Schlessman JL, Garcia-Moreno BE. Molecular determinants of the $\mathrm{pK}(\mathrm{a})$ values of Asp and Glu residues in staphylococcal nuclease. Proteins 2009;77:570-588.

5. Chimenti MS, Castaneda CA, Majumdar A, Garcia-Moreno B. Structural origins of high apparent dielectric constants experienced by ionizable groups in the hydrophobic core of a protein. J Mol Biol 2010; doi10.1016.2010.10.001.

6. Fitch CA, Karp DA, Lee KK, Stites WE, Lattman EE, Garcia-Moreno EB. Experimental $\mathrm{pK}(\mathrm{a})$ values of buried residues: analysis with continuum methods and role of water penetration. Biophys J 2002;82:3289-3304.

7. Isom DG, Cannon BR, Castaneda CA, Robinson A, Garcia-Moreno B. High tolerance for ionizable residues in the hydrophobic interior of proteins. Proc Natl Acad Sci USA 2008;105:17784-17788.

8. Karp DA, Gittis AG, Stahley MR, Fitch CA, Stites WE, Garcia-Moreno EB. High apparent dielectric constant inside a protein reflects structural reorganization coupled to the ionization of an internal Asp. Biophys J 2007;92:2041-2053.

9. Karp DA, Stahley MR, Garcia-Moreno B. Conformational consequences of ionization of Lys, Asp, and Glu buried at position 66 in staphylococcal nuclease. Biochemistry 2010;49:4138-4146.

10. Takayama Y, Castaneda CA, Chimenti M, Garcia-Moreno B, Iwahara J. Direct evidence for deprotonation of a lysine side chain buried in the hydrophobic core of a protein. J Am Chem Soc 2008;130:6714-6715.

11. Zheng Z, Sosnick TR. Protein vivisection reveals elusive intermediates in folding. J Mol Biol 2010;397:777-788.

12. Royer CA. Revisiting volume changes in pressure-induced protein unfolding. Biochim Biophys Acta 2002;1595:201-209.

13. Silva JL, Foguel D, Royer CA. Pressure provides new insights into protein folding, dynamics and structure. Trends Biochem Sci 2001;26:612-618.

14. Brun L, Isom DG, Velu P, Garcia-Moreno B, Royer CA. Hydration of the folding transition state ensemble of a protein. Biochemistry 2006; 45:3473-3480.

15. Mitra L, Hata K, Kono R, Maeno A, Isom D, Rouget JB, Winter R, Akasaka K, Garcia-Moreno B, Royer CA. V(i)-value analysis: a pressure-based method for mapping the folding transition state ensemble of proteins. J Am Chem Soc 2007;129:14108-14109.

16. Mitra L, Rouget JB, Garcia-Moreno B, Royer CA, Winter R. Towards a quantitative understanding of protein hydration and volumetric properties. Chemphyschem 2008;9:2715-2721.

17. Panick G, Malessa R, Winter R, Rapp G, Frye KJ, Royer CA. Structural characterization of the pressure-denatured state and unfolding/refolding kinetics of staphylococcal nuclease by synchrotron small-angle X-ray scattering and Fourier-transform infrared spectroscopy. J Mol Biol 1998;275:389-402.

18. Panick G, Vidugiris GJ, Malessa R, Rapp G, Winter R, Royer CA. Exploring the temperature-pressure phase diagram of staphylococcal nuclease. Biochemistry 1999;38:4157-4164.

19. Woenckhaus J, Kohling R, Thiyagarajan P, Littrell KC, Seifert S, Royer CA, Winter R. Pressure-jump small-angle X-ray scattering detected kinetics of staphylococcal nuclease folding. Biophys $\mathrm{J}$ 2001;80:1518-1523.

20. Lassalle MW, Yamada H, Morii H, Ogata K, Sarai A, Akasaka K. Filling a cavity dramatically increases pressure stability of the cMyb R2 subdomain. Proteins 2001;45:96-101.

21. Akasaka K, Li H. Low-lying excited states of proteins revealed from nonlinear pressure shifts in ${ }^{1} \mathrm{H}$ and ${ }^{15} \mathrm{~N}$ NMR. Biochemistry 2001;40:8665-8671.

22. Akasaka K. Highly fluctuating protein structures revealed by variable-pressure nuclear magnetic resonance. Biochemistry 2003;42:10875-10885.

23. Akasaka K. Probing conformational fluctuation of proteins by pressure perturbation. Chem Rev 2006;106:1814-1835.

24. Bezsonova I, Korzhnev DM, Prosser RS, Forman-Kay JD, Kay LE. Hydration and packing along the folding pathway of SH3 domains by pressure-dependent NMR. Biochemistry 2006;45:4711-4719.

25. Korzhnev DM, Bezsonova I, Evanics F, Taulier N, Zhou Z, Bai Y, Chalikian TV, Prosser RS, Kay LE. Probing the transition state ensemble of a protein folding reaction by pressure-dependent NMR relaxation dispersion. J Am Chem Soc 2006;128:5262-5269.

26. Korzhnev DM, Kay LE. Probing invisible, low-populated states of protein molecules by relaxation dispersion NMR spectros- 
copy: an application to protein folding. Acc Chem Res 2008;41: $442-451$.

27. Kataoka M, Nishii I, Fujisawa T, Ueki T, Tokunaga F, Goto Y. Structural characterization of the molten globule and native states of apomyoglobin by solution X-ray scattering. J Mol Biol 1995;249:215-228.

28. Svergun DI, Koch MHJ. Small-angle scattering studies of biological macromolecules in solution. Rep Prog Phys 2003:1735-1782.

29. Franke D, Svergun DI. DAMMIF, a program for rapid ab-initio shape determination in small-angle scattering. J Appl Cryst 2009;42:342-346.

30. Akasaka K. Highly fluctuating protein structures revealed by variable-pressure nuclear magnetic resonance. Biochemistry 2003;42: 10875-10885.

31. Kohn JE, Millett IS, Jacob J, Zagrovic B, Dillon TM, Cingel N, Dothager RS, Seifert S, Thiyagarajan P, Sosnick TR, Hasan MZ, Pande VS, Ruczinski I, Doniach S, Plaxco KW. Random-coil behavior and the dimensions of chemically unfolded proteins. Proc Natl Acad Sci USA 2004;101:12491-12496.

32. Rouget JB, Schroer MA, Jeworrek C, Pühse M, Saldana JL, Bessin Y, Tolan M, Barrick D, Winter R, Royer CA. Unique features of the folding landscape of a repeat protein revealed by pressure perturbation. Biophys J 2010;98:2712-2721.

33. Kobashigawa Y, Sakurai M, Nitta K. Effect of hydrostatic pressure on unfolding of alpha-lactalbumin: volumetric equivalence of the molten globule and unfolded state. Protein Sci 1999;8:2765-2772.

34. Peng X, Jonas J, Silva JL. Molten-globule conformation of Arc repressor monomers determined by high-pressure ${ }^{1} \mathrm{H}$ NMR spectroscopy. Proc Natl Acad Sci USA 1993;90:1776-1780.

35. Ruan K, Lange R, Bec N, Balny C. A stable partly denatured state of trypsin induced by high hydrostatic pressure. Biochem Biophys Res Commun 1997;239:150-154.

36. Damjanovic A, Schlessman JL, Fitch CA, Garcia AE, Garcia-Moreno EB. Role of flexibility and polarity as determinants of the hydration of internal cavities and pockets in proteins. Biophys J 2007;93: 2791-2804.

37. Ghosh N, Cui Q. pKa of residue 66 in Staphylococal nuclease. I. Insights from QM/MM simulations with conventional sampling. J Phys Chem B 2008;112:8387-8397.

38. Zheng L, Chen M, Yang W. Random walk in orthogonal space to achieve efficient free-energy simulation of complex systems. Proc Natl Acad Sci USA 2008;105:20227-20232.
39. Ropars V, Bouguet-Bonnet S, Auguin D, Barthe P, Canet D, Roumestand C. Unraveling protein dynamics through fast spectral density mapping. J Biomol NMR 2007;37:159-177.

40. Barthe P, Ropars V, Roumestand C. DYNAMOF: a program for the dynamics analysis of relaxation data obtained at multiple magnetic fields. In: $2006.513 \mathrm{p}$.

41. Bai Y, Milne JS, Mayne L, Englander SW. Primary structure effects on peptide group hydrogen exchange. Proteins 1993;17:75-86.

42. Yamada H, Nishikawa K, Honda M, Shimura T, Tabayashi K, Akasaka K. Pressure-resisting cell for high-pressure, high-resolution nuclear magnetic resonance measurements at very high magnetic fields. Rev Sci Instrum 2001;72:1463-1471.

43. Royer CA, Smith WR, Beechem JM. Analysis of binding in macromolecular complexes: a generalized numerical approach. Anal Biochem 1990;191:287-294.

44. Royer CA, Beechem JM. Numerical analysis of binding data: advantages, practical aspects, and implications. Methods Enzymol 1992; 210:481-505.

45. Neumann RC, Jr., Kauzmann W, Zipp A. Pressure dependence of weak acid ionization in aqueous buffers. J Phys Chem 1973:2687-2693.

46. Javid N, Vogtt K, Krywka C, Tolan M, Winter R. Protein-protein interactions in complex cosolvent solutions. ChemPhysChem 2007;8:679-689.

47. Krywka C, Sternemann C, Paulus M, Javid N, Winter R, Al-Sawalmih A, Yi S, Raabe D, Tolan M. The small-angle and wide-angle Xray scattering set-up at beamline BL9 of DELTA. J Synchrotron Rad 2007;14:251.

48. Roth SV, Dohrmann R, Dommach M, Kuhlmann M, Kroger I, Gehrke R, Walter H, Schroer C, Lengeler B, Müller-Buschbaum P. Small-angle options of the upgraded ultrasmall-angle X-ray scattering beamline BW4 at HASYLAB. Rev Sci Instrum 2006;77:085106.

49. Krywka C, Sternemann C, Paulus M, Tolan M, Royer C, Winter R. Effect of osmolytes on pressure-induced unfolding of proteins: A high-pressure SAXS study. ChemPhysChem 2008;9:2809-2815.

50. Lindner P, Zemb T. Neutrons, X-rays and light: scattering methods applied to soft condensed matter. Amsterdam: Elsevier Science; 2002.

51. Svergun DI. Determination of regularization parameter in indirect-transform methods using perceptual criteria. J Appl Cryst 1992;25:495-503.

52. Kozin MB, Svergun DI. Automated matching of high- and low-resolution structural models. J Appl Cryst 2001;34:33-41.

53. Volkov VV, Svergun DI. Uniqueness of ab initio shape determination in small-angle scattering. J Appl Cryst 2003;36:860-864. 